\title{
Spreading Peak Demand through Changes in Working and School Hours: The Experience of Clermont-Ferrand
}

\author{
Sarah Moraillon \\ Transport Technologie-Consult Karlsruhe GmbH (TTK), 47 rue Maurice Flandin, Lyon, 69003, France
}

\begin{abstract}
The Transport Authority of Clermont-Ferrand (France) has been facing the challenge of overcrowding on its tramway line for many years. It therefore considered an innovative approach to tackle the issue, by focusing on demand management. The objective is to convince some organizations located along the line to change their working arrangements, so that their employees would avoid travelling during peak hours on the line. TTK, a German-French mobility planning and consulting company, was in charge of studying the opportunity and feasibility of this approach. For that purpose, a model was developed to assess how changes could improve the line overcrowding (or, how they could worsen the situation if not coordinated). This model was developed in-house, as traditional macro-simulation tools cannot be precise enough to understand the impact of 5 or 10 min changes on the line saturation. Model results identified several opportunities, and two organizations took first steps to implement change. Even with the sole participation of those two organizations, the SMTC saw a decrease of 5\% demand at the peak times over a one-year period, a demand spread to off-peak times. This encouraging result led the SMTC to keep working with the organizations to develop this dynamic to other sites.
\end{abstract}

Key words: Light rail, demand management, peak hour, traffic modeling.

\section{Introduction}

Clermont-Ferrand is a city of 150,000 inhabitants in the Auvergne-Rhône-Alpes region of France. It developed a tramway line in 2006, which was extended in 2007 and next 2013. Used by 70,000 passengers on an average day, the line is meeting all forecasted traffic expectations. This success is however threatened by peak hour congestion, which worsens every year as the public transport network faces a $+5 \%$ yearly average demand growth.

The "SMTC", Clermont-Ferrand's transport authority, has studied several ways to tackle this challenge. One of them, the most obvious maybe, was fleet management. The SMTC decided to buy five additional vehicles delivered in 2017. However, due to operational reasons (the headways already being short in peak hours) it now seems difficult to fit in more services during the peaks along the line. New

Corresponding author: Mrs Sarah Moraillon, M.Sc., M.Eng., C.Eng., Deputy director, TTK. vehicles also represent an additional cost, especially for Clermont-Ferrand's system, which uses specific vehicles (rubber-tyred light rail). Therefore, the SMTC thought about new ways of tackling peak congestion, through an action based on demand management. Several studies show indeed that Travel Demand Management (TDM) is an effective way of limiting congestion in peak hours $[1,2]$. Back in 2015, it decided to study the opportunity of developing partnerships with the organizations located along the tramway line. TTK was appointed the study in partnership with another consultancy, to assess whether a change could be feasible and what it could bring to the network.

\section{The Challenge of Modelling Public Transport Demand with Micro-effects on a Tight Time Lapse}

TTK first considered using a macro-simulation modelling tool, splitting the AM and PM period demand matrices into sub-matrices over shorter times. 


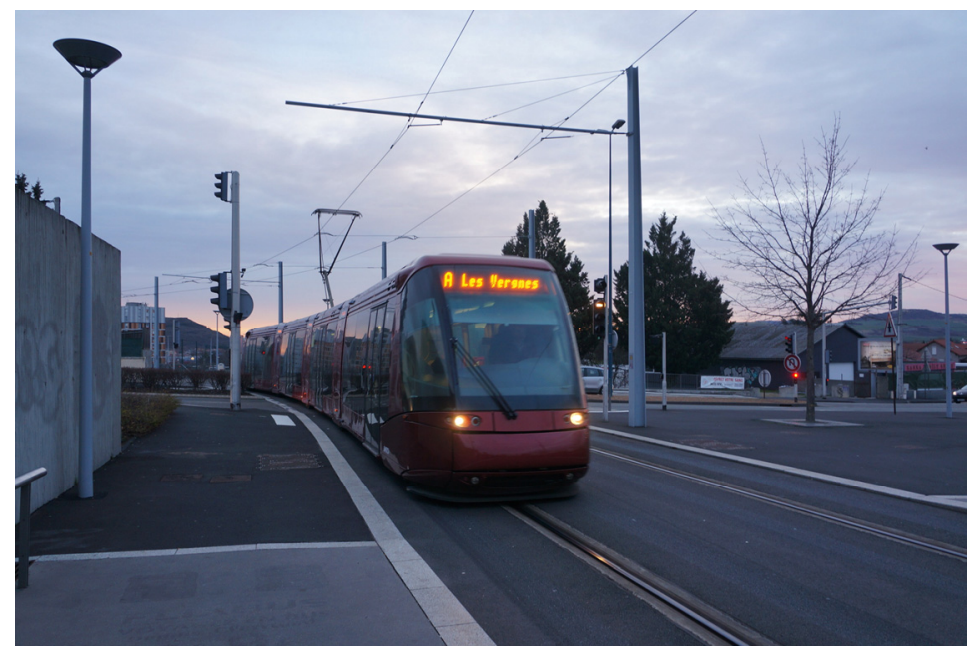

Fig. 1 View of the vehicles (picture $\odot$ TTK).

However, such tools assign the whole trip issued from the demand matrix on the network, even if the trip duration is longer than the considered period. It therefore cannot show only the legs of trips which are made on the network during the considered laps of time.

Therefore, TTK developed a specific model to understand the potential impacts of simultaneously changing several working time arrangements in different organizations situated close to different stops of the line.

The model developed by TTK was based on several steps and could be used for similar assessments.

(1) Determine the number of users concerned by the measure, site by site. Open data was used to select some key organizations located along the line, based on their number of employees. The most interesting organizations were met to discuss the opportunity of a time shift and assess the number of tramway users concerned by the measure.

(2) Among the current public transport users, determine arrival times at work or school. They could be assessed based on good quality data for some organizations, thanks to surveys conducted on site. For the others a normal distribution with standard deviation depending on the organization practices (for example flexibility in arrival times) was usually applied.
(3) Assess the walking travel time between tramway stations and place of work. Some users would come more in advance and walk slowly; some would take the "last possible" service and rush to work. We needed to consider these practices to understand when the targeted people do actually alight their public transport stop.

(4) Take into account origin of the journeys. Some users come from far away and will be aboard the line for a long time, others would actually only travel a few stops. Those travelling long journeys are particularly important to identify because they can contribute to congesting the line on another section if they change their travel pattern by coming later for example.

TTK then modelled several scenarios:

- Scenario A "Do-Nothing". With the line growth, the scenario showed a growing saturation issue.

- Scenario B "Do-As-Organizations-Want". After having met seven of them (the most impacting ones, including schools), we modelled what impacts could have the changes they were ready to implement (start working times 15 min later, split school times with some pupils beginning at 8 am and others at $9 \mathrm{am} . .$.$) .$

- Scenario C "Do-as-Best-for-Transport". In this scenario, we looked for solutions both acceptable for organizations (respecting core hours, school canteen constraints...) and interesting for transport overcrowding. 


Seuil 1 "confort" jusqu'à 2 personnes/m2
158 personnes maxi par $10 \mathrm{~min}$
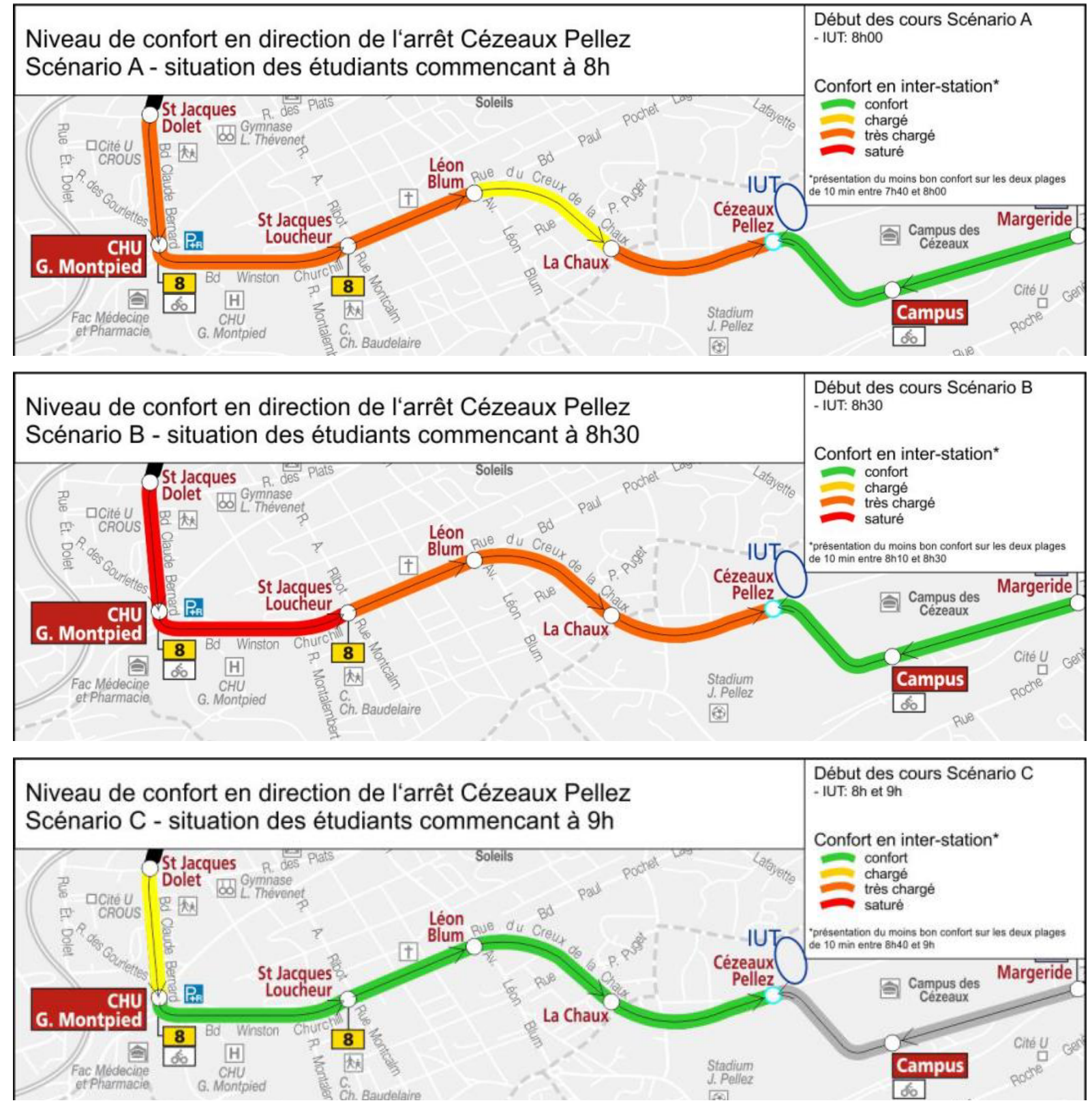

Fig. 2 Example of geographical representation of line overcrowding depending on scenarios (green: comfortable, yellow: crowded, orange: overcrowded, red: saturation). 


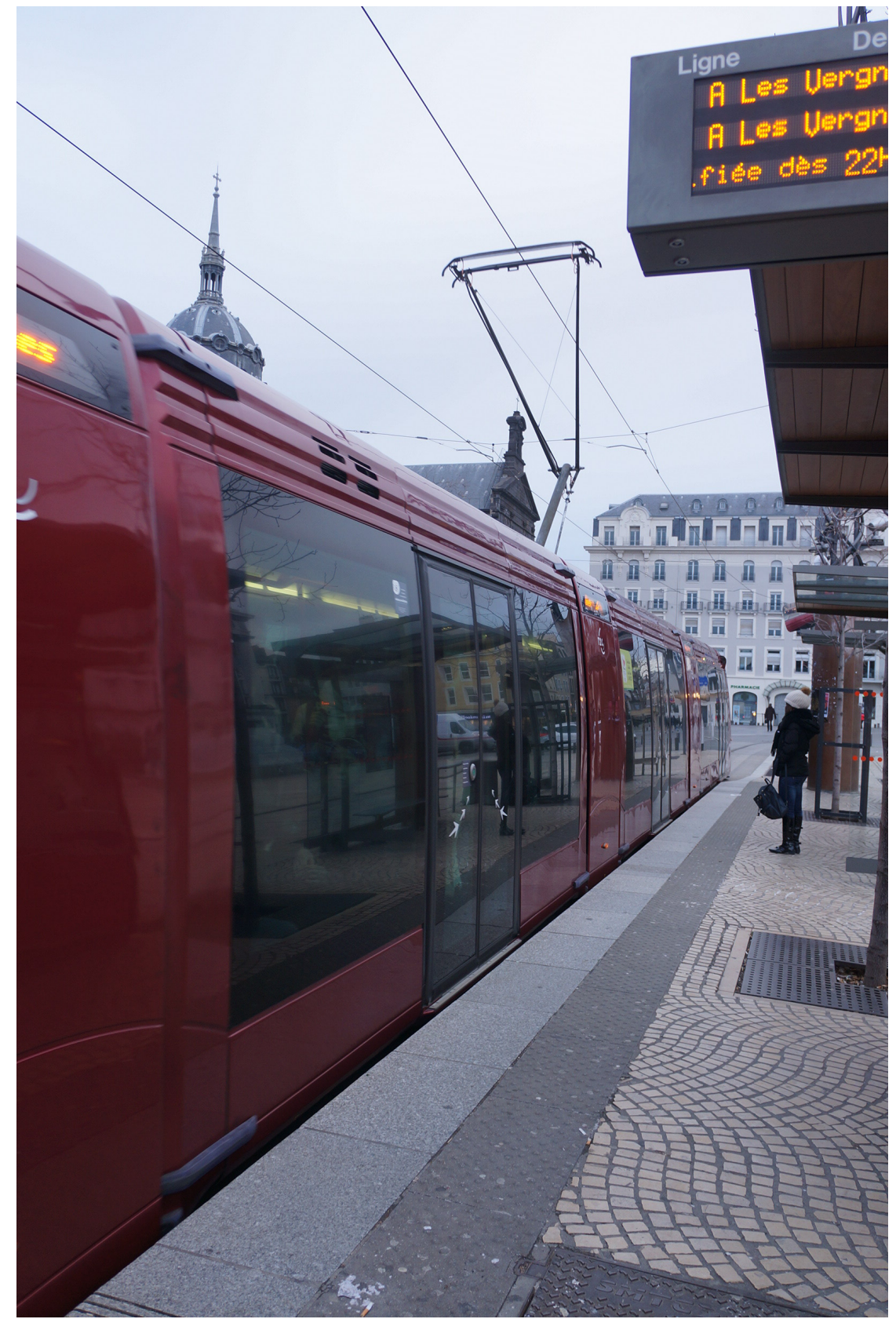

Fig. 3 Picture of the tramway line at a stop (CTTK).

A total of 18 iterations were needed to get an interesting result, due to the complexity of the model: a change of working arrangements in just one organization changes the saturation profile of the whole line, both in- and outbound, and am and pm. It was a real challenge to come to a balanced scenario resulting in congestion improvements along the whole line, for the am and pm, in both directions, and resulting in improvements of the journey comfort of participating organizations' passengers. This was particularly true as the peak profile is not very concentrated on a high peak but presents many smaller high peaks.

\section{Useful Model Results to Determine the} Best Options for Changing Working Hours/School Hours

Results showed: 
- Congestion issues were reinforced in scenario A;

- Scenario B had locally positive but also negative impacts.

For example, the University "Les Cézeaux" considered starting courses at 8:30am instead of 8am. This showed a negative impact on tramway line congestion as the tramway is already nearly saturated at 8:15am a few stops before, and the students would have contributed to strengthen the problem

- Scenario C showed much better results with the integration of cross-effects and a "win-win" solution.

\section{A Successful First Implementation, which Does Reinforce the Need for Full Determination and Perseverance to Develop the Approach to Other Organizations}

Among the seven-targeted organizations, two of them have decided to change their time arrangements:

- One of them, a high school, spitted school hours at 8 am for half of the students and 9 am for the other half.

- The other, a university, decided to start lecture time at 7:45 am instead of $8 \mathrm{am}$.

The operator conducted a first assessment of those measures, comparing 2016 and 2017 demand profile on the line by 15 min steps of time.

This evaluation showed a reduction of $5 \%$ of the highest peak demand (am), or around 15 persons less to be transported per vehicle.

\section{Conclusions}

The study led by TTK has already encouraged some organizations to change their time arrangements in order to prevent overcrowding on the tramway line. A $5 \%$ reduction of the peak demand has been registered, after just one year of change, a result achieved with the sole participation of two organizations.

The SMTC is now working to broaden the scope of this approach through developed mobility management tools (it is mandatory in France since 2018 for organizations with more than 100 employees in cities to develop a workplace travel plan).

Lessons learnt include:

- The need for cooperation with the organizations is essential, as they are the ones to actually implement the change. They remain free to do so: they need to be convinced of the benefits of the change, and barriers to change need to be addressed internally.

- A modelling tool represents a real added value to assess the options and avoid any side effect that an organization could make on the line overcrowding, by changing its working or school hours.

- The approach combining several organizations - all selected due to their size and localization close to the line-was innovative and has led to multiply the potential of change on the public transport conditions on the network.

- Reducing peak travel demand is possible, and can even be achieved through time changes in a limited number of involved organisations, as long as they play an important role in the local public transport demand.

\section{References}

[1] Brick, E., and Moraillon, S. 2014. "Achieving Peak Travel Demand Reduction through a Travel Behaviour Programme: Singapore Example." In Proceedings of the ITRN, 8.

[2] Victoria Transport Policy Institute. 2010. TDM Encyclopedia. Alternative Work Schedules. 